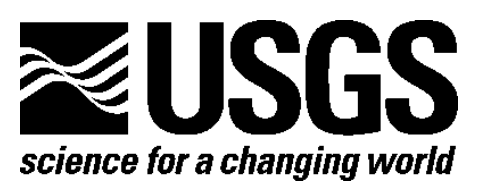

\title{
Distribution of Potential Hydrothermally Altered Rocks in Central Colorado Derived From Landsat Thematic Mapper Data: A Geographic Information System Data Set
}

By Daniel H. Knepper, Jr.

Open-File Report 2010-1076

U.S. Department of the Interior

U.S. Geological Survey 


\section{U.S. Department of the Interior \\ KEN SALAZAR, Secretary}

\section{U.S. Geological Survey \\ Marcia K. McNutt, Director}

U.S. Geological Survey, Reston, Virginia: 2010

For product and ordering information:

World Wide Web: http://www.usgs.gov/pubprod

Telephone: 1-888-ASK-USGS

For more information on the USGS-the Federal source for science about the Earth, its natural and living resources, natural hazards, and the environment:

World Wide Web: http://www.usgs.gov

Telephone: 1-888-ASK-USGS

Suggested citation:

Knepper, D.H., Jr., 2010, Distribution of potential hydrothermally altered rocks in central Colorado derived from Landsat Thematic Mapper data: A geographic information system data set: U.S. Geological Survey Open-File Report 2010-1076, 14 p.

Any use of trade, product, or firm names is for descriptive purposes only and does not imply endorsement by the U.S. Government.

Although this report is in the public domain, permission must be secured from the individual copyright owners to reproduce any copyrighted material contained within this report. 


\section{Contents}

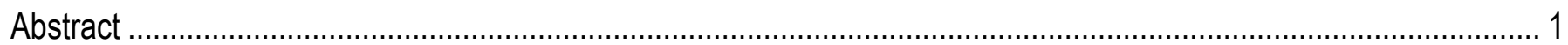

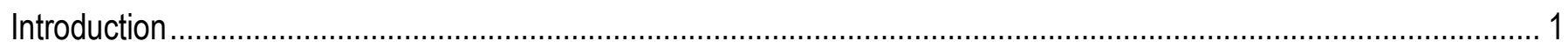

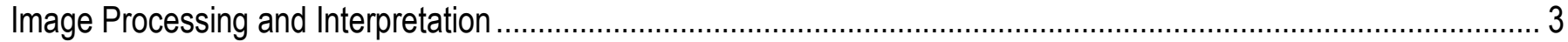

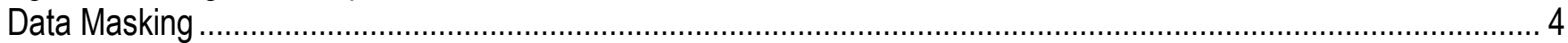

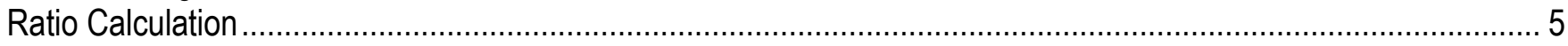

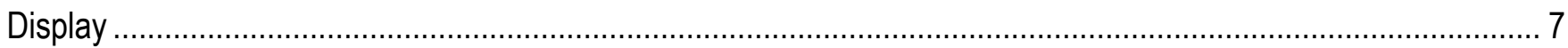

Visual Image Mosaic Interpretation .......................................................................................................... 8

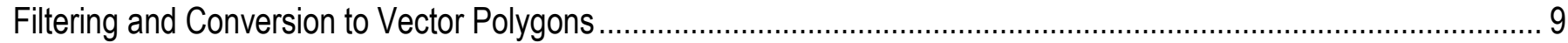

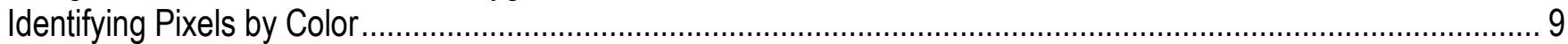

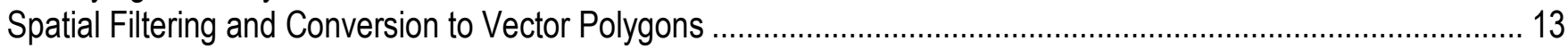

Characteristics of Potential Alteration Shapefile (TM_potential_alteration.shp) ..................................................... 13

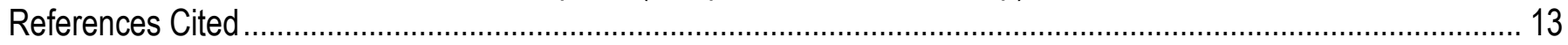

\section{Figures}

1. Central Colorado Assessment Project (CCAP) study area showing footprints of Landsat Thematic Mapper (TM) scenes used to prepare the map of potential hydrothermally altered rocks in central Colorado.

Characteristics of the scenes are shown in table 1.

2. Laboratory reflectance spectra of common vegetation and hydrothermal alteration minerals and the Landsat Thematic Mapper (TM) spectral bands (1-5,7). The kaolinite spectrum shows a characteristic absorption doublet near 2.2 micrometers that produces high $5 / 7$ ratio values. The hematite spectrum has a characteristically steep slope in the visible region that produces high $3 / 1$ ratio values. The Normalized Difference Vegetation Index (NDVI) used to identify pixels dominated by green vegetation takes advantage of the large reflectance difference between band 3 and band 4

3. Landsat Thematic Mapper color-ratio composite image mosaic of the Central Colorado Assessment Project (CCAP) study area. Insets show the spectral response of color-ratio composite images in areas of hydrothermally altered rocks in well-known mineral districts and provide an indication of the level of detail that is attained with the Landsat data.

4. Generalized colors obtained by color addition of combined red, green, and blue images. The three Landsat Thematic Mapper (TM) ratio images (5/7, 3/1,5/4) were combined as red, green, and blue, respectively. Pixels with a high $5 / 7$ ratio will have large red component. Large $3 / 1$ ratio values will give a pixel a large green component. Since vegetation was filtered out prior to combining the three ratio images, the high $5 / 4$ ratio values produced by bare ground (and some ferric and ferrous iron minerals) will give each pixel a blue component. By recognizing the basic hues produced by color addition (red, magenta, blue, cyan, green, yellow, and white), the general composition derived from the spectral information can be inferred.

5. Range of hue values (0-360) produced during conversion composite images of Red-Green-Blue color coordinates to Munsell color coordinates and the position of the six basic hues

6. Filtered and vectorized Landsat Thematic Mapper (TM) color-ratio composite image mosaic data of the Central Colorado Assessment Project (CCAP) study area showing areas of potentially hydrothermally altered rocks. Insets show hydrothermally altered rocks in well-known mineral districts and provide an indication of the level of detail that is attained with the vectorized Landsat data analysis. 


\section{Tables}

1. Landsat 7 Thematic Mapper (TM) scenes covering the Central Colorado Assessment Project study area. These data are available at no cost through the United States Geological Survey EROS Data Center and can be downloaded from URL http://edcsns17.cr.usgs.gov/EarthExplorer/

2. Criteria for classifying Landsat TM color-ratio composite image mosaic for conversion to vector polygons 


\title{
Distribution of Potential Hydrothermally Altered Rocks in Central Colorado Derived From Landsat Thematic Mapper Data: A Geographic Information System Data Set
}

By Daniel H. Knepper, Jr.

\begin{abstract}
As part of the Central Colorado Mineral Resource Assessment Project, the digital image data for four Landsat Thematic Mapper scenes covering central Colorado between Wyoming and New Mexico were acquired and band ratios were calculated after masking pixels dominated by vegetation, snow, and terrain shadows. Ratio values were visually enhanced by contrast stretching, revealing only those areas with strong responses (high ratio values). A color-ratio composite mosaic was prepared for the four scenes so that the distribution of potentially hydrothermally altered rocks could be visually evaluated. To provide a more useful input to a Geographic Information System-based mineral resource assessment, the information contained in the color-ratio composite raster image mosaic was converted to vectorbased polygons after thresholding to isolate the strongest ratio responses and spatial filtering to reduce vector complexity and isolate the largest occurrences of potentially hydrothermally altered rocks.
\end{abstract}

\section{Introduction}

From 2004 to 2008, the United States Geological Survey (USGS) Central Colorado Assessment Project (CCAP) was charged with conducting a mineral resource assessment of Federal lands, primarily U.S. National Forest land, in central Colorado (fig. 1). As part of the mineral resource assessment, Landsat Thematic Mapper (TM) imagery data were used to help target areas where the exposed rocks might be hydrothermally altered, providing an indication of the location of potentially mineralized areas that may contain mineral deposits. 


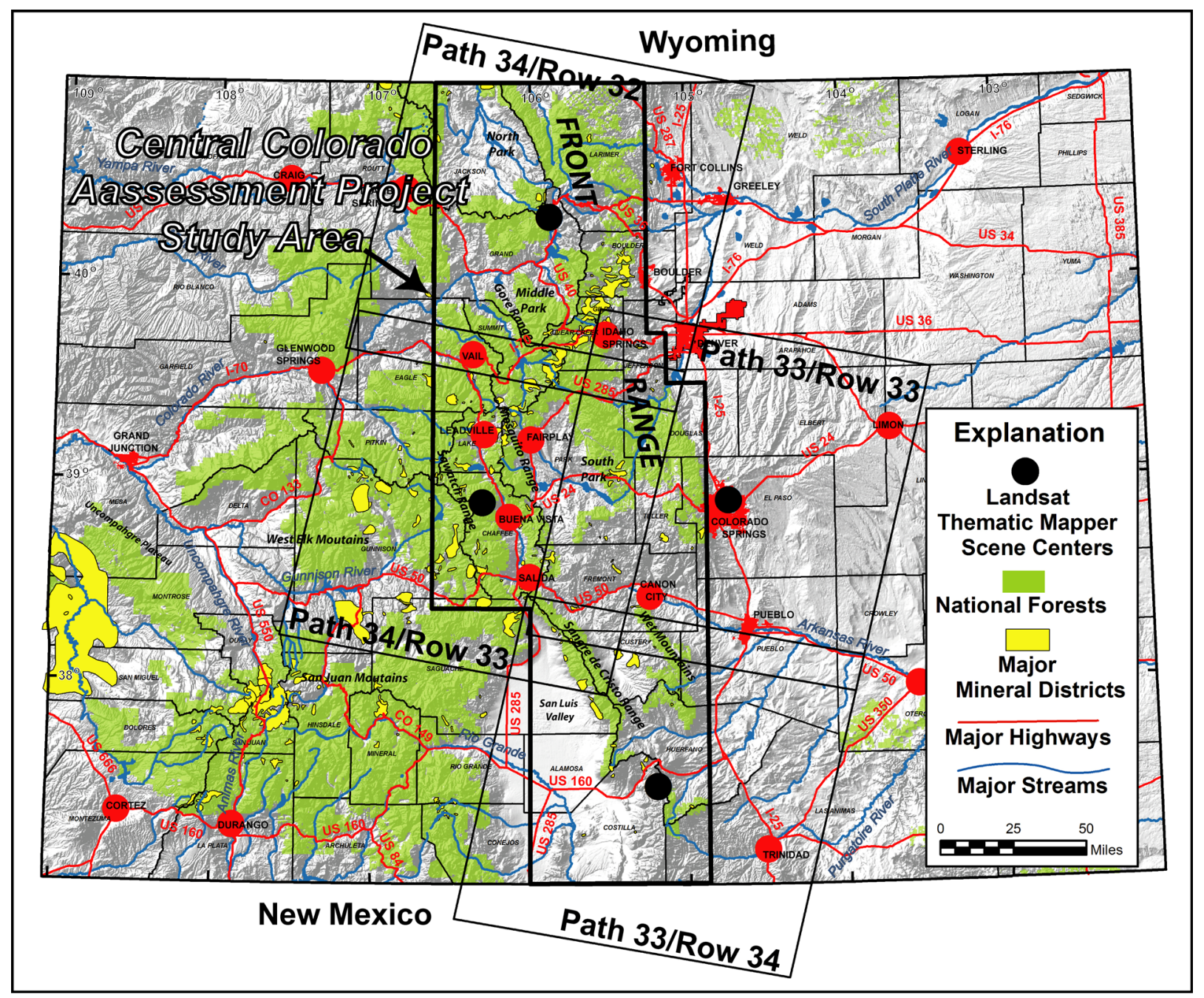

Figure 1. Central Colorado Assessment Project (CCAP) study area showing footprints of Landsat Thematic Mapper (TM) scenes used to prepare the map of potential hydrothermally altered rocks in central Colorado. Characteristics of the scenes are shown in table 1.

Landsat TM is a broadband satellite imaging system that measures reflected solar radiation from an array of 30 meter square pixels on the Earth's surface in six bands of the visible, near-infrared, and shortwave-infrared portions of the electromagnetic spectrum (National Aeronautics and Space Administration, 2009) (fig. 2). Many materials can be identified and mapped on a regional scale using the information from the six TM spectral bands, including vegetation, water, snow, cultural features (cities, roads, railroads, and so forth), and rocks and soils. Images formed by the ratios between selected TM bands can be used to detect the presence of two broad groups of minerals in exposed rocks and soils. One mineral group includes ferric minerals, such as hematite, goethite, and jarosite. The second mineral group is more diverse and includes clay (for example kaolinite and montmorillonite), carbonate (for example calcite and dolomite), sulfate (for example gypsum and alunite), and mica (for example muscovite and chlorite) minerals. Many of these minerals commonly form in rocks that have been hydrothermally altered, or by the weathering of hydrothermally altered rocks. But many of the minerals in these two mineral groups are not unique to hydrothermally altered rocks. 


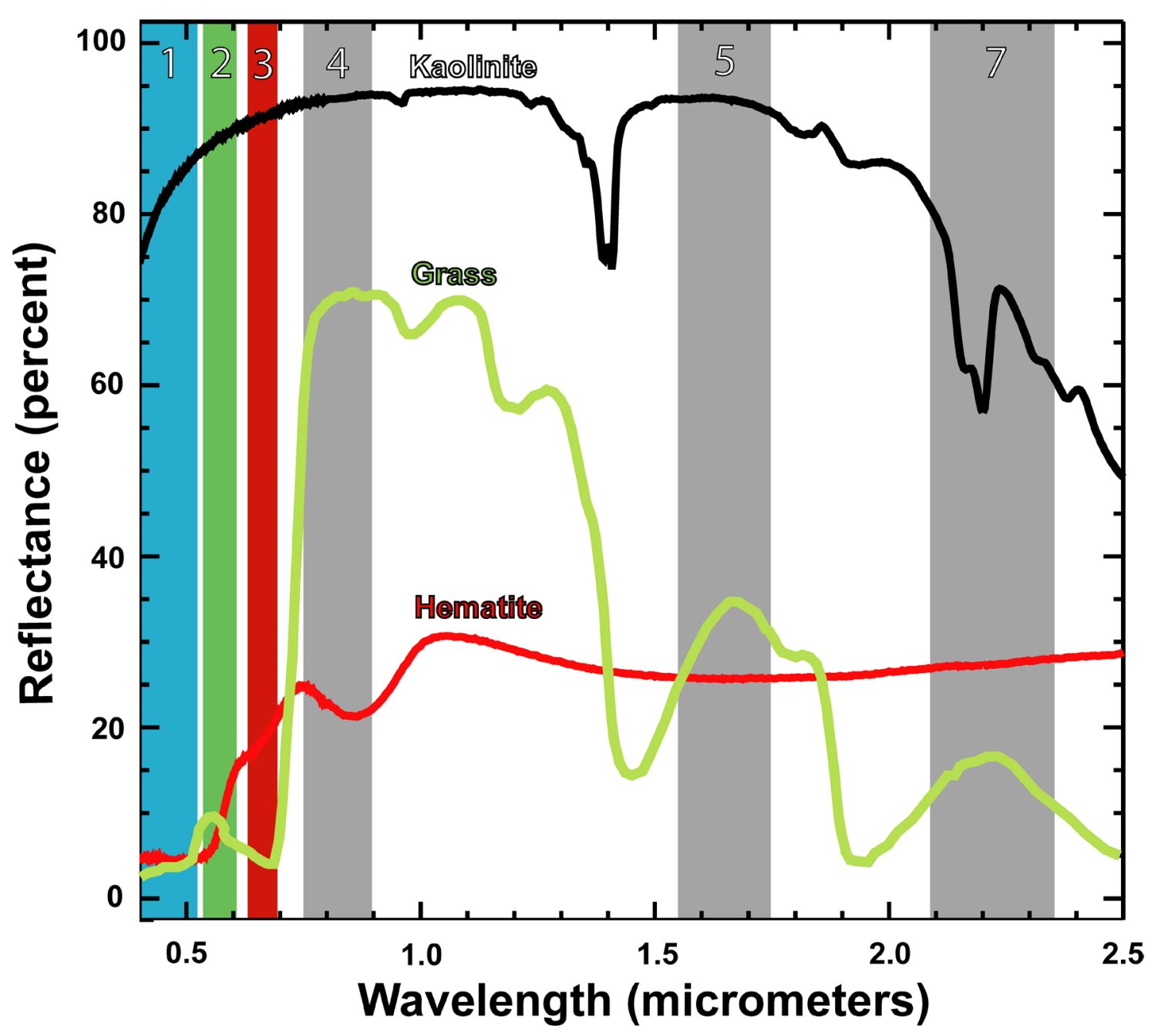

Figure 2. Laboratory reflectance spectra of common vegetation and hydrothermal alteration minerals and the Landsat Thematic Mapper (TM) spectral bands (1-5,7). The kaolinite spectrum shows a characteristic absorption doublet near 2.2 micrometers that produces high $5 / 7$ ratio values. The hematite spectrum has a characteristically steep slope in the visible region that produces high $3 / 1$ ratio values. The Normalized Difference Vegetation Index (NDVI) used to identify pixels dominated by green vegetation takes advantage of the large reflectance difference between band 3 and band 4 .

Preparation of the map of potentially hydrothermally altered rocks in central Colorado was conducted in two steps. The first step applied various image processing procedures designed to prepare a color-ratio composite image mosaic that could be visually analyzed for areas containing the ferric iron and clay-carbonate-sulfate-mica mineral groups. The second step consisted of (a) filtering to coalesce pixel concentrations of the two mineral groups and eliminate isolated single pixels of the mineral groups and (b) conversion of the raster color-ratio composite mosaic to ArcGIS vector shapefiles for use in the mineral resource assessment.

\section{Image Processing and Interpretation}

A variety of digital image processing techniques were used in preparing the color-ratio composite image mosaic of the four Landsat TM scenes of central Colorado (fig. 1 and table 1) required 
to cover the Central Colorado Assessment Project study area. The primary criteria for selecting TM scenes to process were that they had to be cloud free and snow free and have as high a solar elevation angle as possible. In Colorado, cloud-free data are most abundant in the fall and midwinter. Midwinter data, however, invariably contain abundant snow, as well as the lowest annual sun angle. Therefore, most of the TM images used for this study were acquired in the fall. The TM scene centered on Colorado Springs (Path 33/Row 33 in figure 1), acquired in July of 2002, was the only recent summer scene lacking significant cloud cover.

Table 1. Landsat 7 Thematic Mapper (TM) scenes covering the Central Colorado Assessment Project study area. These data are available at no cost through the United States Geological Survey EROS Data Center and can be downloaded from URL http://edcsns17.cr.usgs.gov/EarthExplorer/.

\begin{tabular}{|c|l|c|c|}
\hline Path/row & Scene identification number & Acquisition date & Sun elevation (degrees) \\
\hline $33 / 33$ & L71033033_03320020718 & July 18, 2002 & 62.153 \\
\hline $33 / 34$ & L71033034_03419991014 & Oct. 14, 1999 & 41.040 \\
\hline $34 / 32$ & L71034032_03220010924 & Sept. 24, 2001 & 44.777 \\
\hline $34 / 33$ & L71034033_03320010924 & Sept. 24, 2001 & 45.868 \\
\hline
\end{tabular}

Image processing involved three basic steps: (1) masking pixels lacking pertinent spectral information about the composition of rocks and soils, (2) calculating the band ratios for each individual Landsat scene, and (3) visually blending and mosaicing the individual scene color-ratio composites for display by manual contrast stretching.

\section{Data Masking}

Before calculating the TM band ratios, selected pixels of the data were excluded from the analysis. Pixels dominated by vegetation obscure the ground surface so that compositional characteristics of rocks and soils cannot be evaluated from the Landsat data. More importantly, though, TM band 5/TM band 7 (5/7) ratio values for vegetation are indistinguishable from TM 5/7 ratios of the clay-carbonate-sulfate-mica minerals used to identify the presence of potential hydrothermally altered rocks (fig. 2). Consequently, a TM Normalized Difference Vegetation Index (NDVI) (Rouse and others, 1973) was generated and used to identify the vegetation pixels and eliminate them from further analysis. The NDVI is calculated:

$$
\mathrm{NDVI}=\frac{\mathrm{TM} \text { band } 4-\mathrm{TM} \text { band } 3}{\mathrm{TM} \text { band } 4+\mathrm{TM} \text { band } 3}
$$

Possible NDVI values range from -1 to +1 with values more than $0.1-0.2$ generally indicative of vegetation.

Similarly, image data from areas of terrain shadow characteristically have low Data Numbers (DN) in all bands because of the low illumination. Ratio values of these low DN often are very high and commonly cause false anomalies of either the ferric iron or the clay-carbonate-sulfate-mica mineral groups. TM band 4 was visually evaluated to determine the range of low DN that defines shadowed areas and these pixels also were eliminated from further analysis; this process also eliminates most water bodies because radiation in TM band 4 is strongly absorbed by water (in other words, low DNs). Water bodies commonly produce false anomalies of the clay-carbonate-sulfate-mica mineral group. Clouds and residual snow are minor components of the image data, so masking for these features was not necessary. 


\section{Ratio Calculation}

Because Landsat TM reflective data only have six broad bands, TM reflectance spectra are too generalized to allow the identification of individual minerals. However, groups of minerals with strong absorption bands at similar wavelengths can be detected by ratioing TM bands to enhance the presence of these absorption bands.

One group (clay-carbonate-sulfate-mica minerals) is characterized by strong absorption near 2.22.3 micrometers $(\mu \mathrm{m})$, which occurs in TM band 7, and includes hydroxyl-bearing minerals (for example, clay and mica minerals), hydrated sulfates (for example gypsum and alunite), and carbonate minerals (calcite and dolomite) (see kaolinite spectrum in fig. 2). The TM 5/7 ratio is used to detect the strong absorption of the clay-carbonate-sulfate-mica group minerals in TM band 7 (Knepper, 1989 and references therin). Because of the strong absorption, the DN in TM band 7 are low, producing high ratio values. The $5 / 7$ ratio values are color coded red on the color-ratio composite image map; the brighter the red, the higher the ratio value and the stronger the apparent absorption in TM band 7 (fig. 3). 

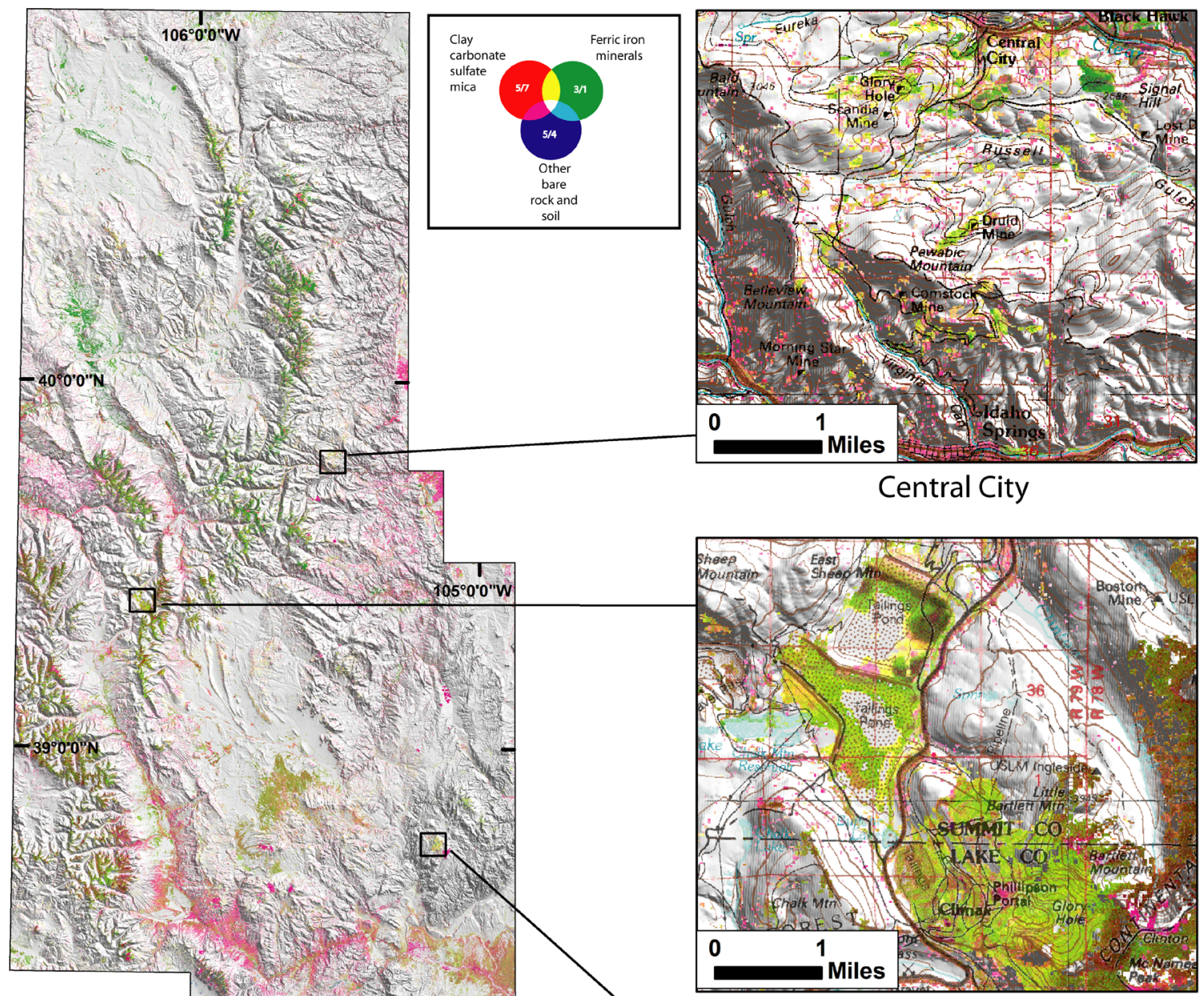

Climax
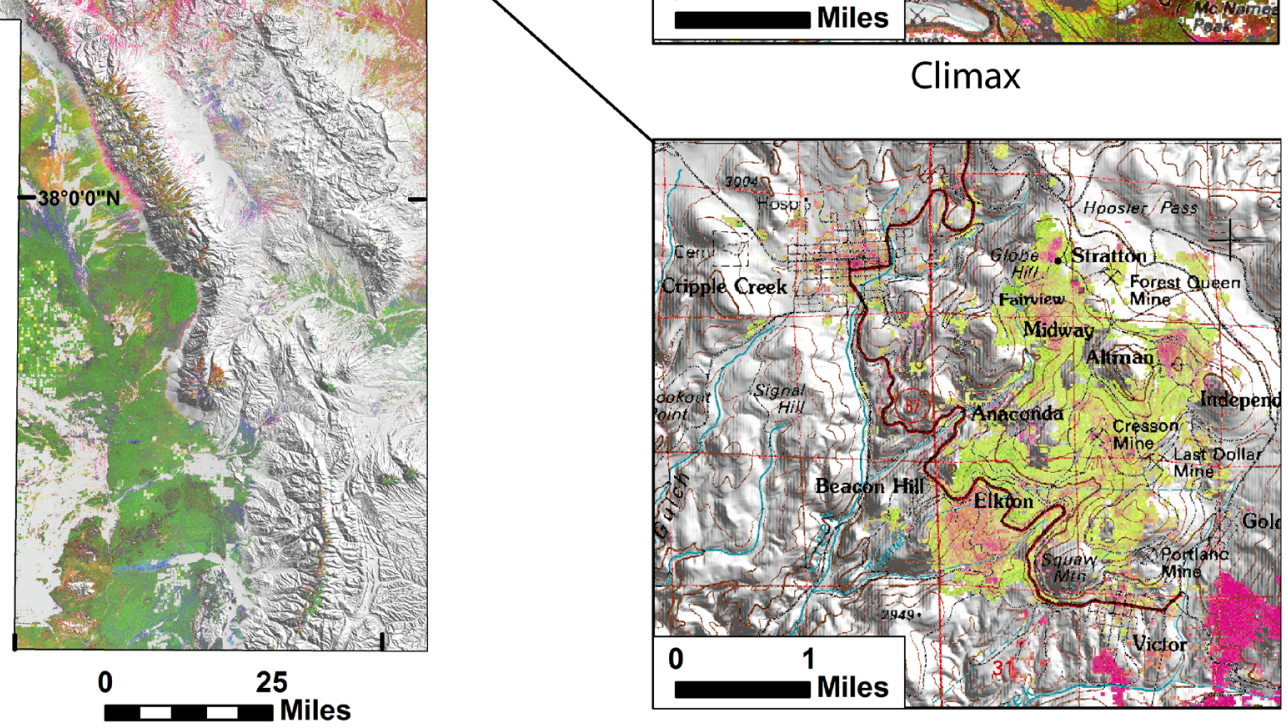

Cripple Creek

Figure 3. Landsat Thematic Mapper color-ratio composite image mosaic of the Central Colorado Assessment Project (CCAP) study area. Insets show the spectral response of color-ratio composite images in areas of hydrothermally altered rocks in well-known mineral districts and provide an indication of the level of detail that is attained with the Landsat data. 
The second group is typified by ferric iron minerals (including hematite, goethite, and jarosite) that typically are shades of red, yellow, and orange in the visible region of the electromagnetic spectrum and have strong absorption in the ultraviolet portion of the spectrum that also strongly affects TM bands 1 (blue) and 2 (green). The TM 3/1 ratio is used to detect the reddish colors that ferric iron minerals give to rocks and soils (see hematite spectrum in fig. 2). The red colors are expressed as high DN values in TM band 3 (red band) and low DN values in TM band 1 (blue band) because of the strong absorption in the ultraviolet and blue portion of the spectrum. Consequently, high 3/1 ratio values are indicative of the presence of minerals of the ferric iron mineral group. The 3/1 ratio values on the map are color-coded in shades of green such that the brighter greens reflect higher ratio values (fig. 3 ).

A third TM band ratio, $5 / 4$, is used in TM color-ratio composite images specifically to visually separate high $5 / 7$ ratio values caused by vegetation from those caused by clay-carbonate-sulfate minerals. Because green vegetation is distinctively highly reflective in TM band 4 , the $5 / 4$ ratio values of vegetated areas are low compared to areas of bare rock and soil (compare grass spectrum to kaolinite and hematite spectra in fig. 2). The 5/4 ratio values are color-coded blue on the color-ratio composite image map such that areas with bare rock and soil (high 5/4 values) have a blue component. Since vegetated pixels were eliminated from the analysis using the NDVI mask, the 5/4 ratio serves only as a check that all vegetation was successfully eliminated. Notice in figure 3 that there are abundant magenta pixels (high 5/7 and 5/4 values indicating clay-carbonate-sulfate-mica group minerals) and no obvious red pixels (high $5 / 7$ only possibly indicating green vegetation pixels) indicating that vegetation masking was effective.

\section{Display}

Each nonvegetated pixel in the map area has a 5/7,3/1, and 5/4 ratio value and these values are displayed in red, green, and blue hues, respectively, proportional to their values. The higher the ratio value, the more of its color is represented in the pixel. The respective colors for the three ratio values are combined in the color-ratio composite image map by the color additive process illustrated in figure 4 . High values of only one of the ratio values will be displayed in hues of its respective primary color: red (5/7), green (3/1), or blue (5/4). Two ratios with high values will be displayed as the combination of their two primary colors. For example, a pixel with a high 5/7 ratio (clay-carbonate-sulfate-mica) and a high 3/1 ratio (iron oxide) will be displayed yellow (red + green) if both ratios are of a similar value. If the $5 / 7$ value is higher than the $3 / 1$ value, the pixel will be orange. If the $3 / 1$ is larger than the $5 / 7$, the pixel will be yellowish-green. 


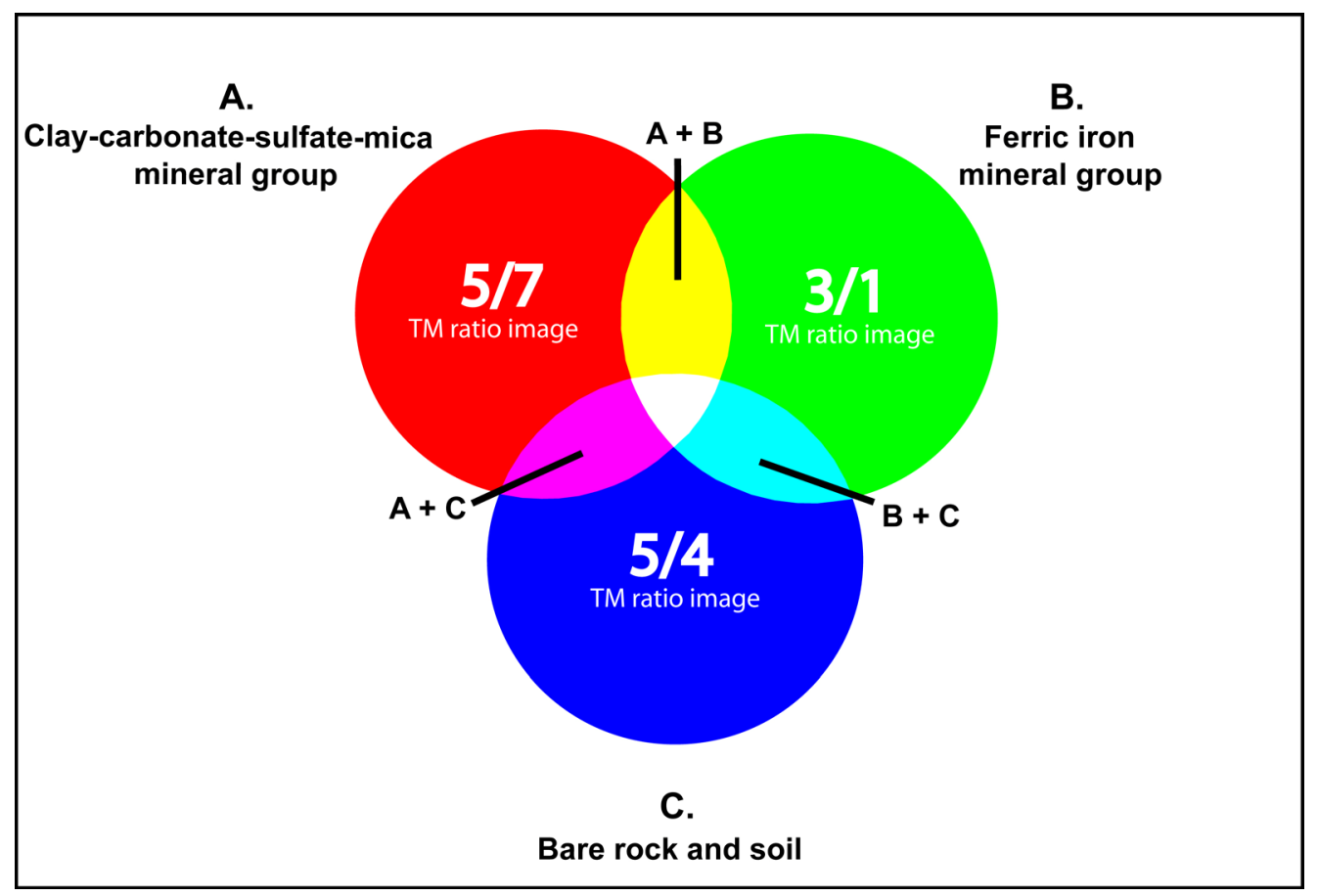

Figure 4. Generalized colors obtained by color addition of combined red, green, and blue images. The three Landsat Thematic Mapper (TM) ratio images $(5 / 7,3 / 1,5 / 4)$ were combined as red, green, and blue, respectively. Pixels with a high 5/7 ratio will have large red component. Large 3/1 ratio values will give a pixel a large green component. Since vegetation was filtered out prior to combining the three ratio images, the high $5 / 4$ ratio values produced by bare ground (and some ferric and ferrous iron minerals) will give each pixel a blue component. By recognizing the basic hues produced by color addition (red, magenta, blue, cyan, green, yellow, and white), the general composition derived from the spectral information can be inferred.

Since green vegetation has been masked, all pixels contain a blue component from moderate to high 5/4 ratio values indicating bare rock and soil. Consequently, high 5/7 (red) also has a blue component and appears in shades of magenta (red + blue). Similarly, pixels bearing ferric iron (high $3 / 1$ values) tend toward cyan hues (blue + green). Visually, the effect of the blue component on a pixel with both high 5/7 and 3/1 ratios is not particularly obvious, but it tends to vary the brightness and shade of yellow, such as seen around the tailings ponds in the Climax area (fig. 3).

\section{Visual Image Mosaic Interpretation}

Since most of the minerals detected by TM ratios are not unique to hydrothermally altered rocks, interpretation of the color-ratio composite image mosaic requires more than just locating and recognizing the colors associated with each mineral group. Clay, carbonate, mica, sulfate, and ferric iron minerals are common in sedimentary rocks and form by the weathering of igneous and metamorphic rocks in the near-surface environment. Consequently, identifying areas that may contain hydrothermally altered rocks requires that the patterns of the detected mineral groups be evaluated. The relation between the mapped mineral groups and landforms that likely are to be lithologically controlled are especially important in identifying the mineral groups that are distinctly related to the lithology of the map units, either the original mineralogy or weathering products derived from the rock unit.

The most straightforward way of interpreting the image map is that: 
Magenta = clay-carbonate-sulfate-mica minerals

Green $=$ ferric iron minerals, mainly iron oxides and hydroxides

Yellow $=$ both clay-carbonate-sulfate-mica and ferric iron minerals.

Variations in the shades of color are not quantitative, but in general, brighter colors indicate higher ratio values and, hence, a stronger indication of the presence of the respective mineral groups. These variations can be caused by the specific mineral species present, the abundance of the minerals, and other materials that may be included in the imaged pixel (mixed pixel).

Although many of the minerals in the two mineral groups are common in hydrothermally altered rocks, most are not unique to hydrothermally altered rocks. For example, sedimentary redbeds, claybearing shales, limestone and dolomite strata, and weathered igneous and metamorphic rocks often contain minerals of the clay-carbonate-sulfate and ferric iron mineral groups, and these types of rocks are common in central Colorado. Consequently, identifying areas of potentially hydrothermally altered rocks depends on recognition of variations in the patterns of the mapped mineral groups, especially abrupt changes in colors and localized concentrations of colors or color combinations. Knowledge of the type and distribution of various rock types in the region also is useful in separating color anomalies because of lithology from those because of hydrothermal alteration. A more complete discussion of the use of Landsat TM data for mapping potentially hydrothermally altered rocks is given by Knepper (1989).

\section{Filtering and Conversion to Vector Polygons}

The green/cyan, magenta, and yellow pixels on the color-ratio composite image mosaic represent the spectral expression of minerals, or groups of minerals, that often are associated with hydrothermally altered rocks or the weathering of hydrothermally altered rocks. The visual identification of these colored pixels on the image mosaic is relatively simple and straightforward; however, direct incorporation of this red-green-blue color raster image information into a Geographic Information System (GIS) analysis is difficult to implement. Secondary maps manually could be drawn to reflect the image information, but this approach requires significant additional time and effort and is partly subjective. Modern image processing and GIS software include routines to convert a raster-based image map into vector polygons after the pixels to be mapped are identified. In other words, if the image data can be converted into a classified image (each pixel DN representing a specific class of information), then the software effectively can produce vector polygons of these classes without further subjective interpretation.

\section{Identifying Pixels by Color}

One of the easiest ways of specifying color is through the usage of Munsell color coordinates (Raines and Knepper, 1983). In the Munsell color system, DN for the orthogonal red, green, and blue ( R, G, B) color components are converted into a cylindrical coordinate system where the color of each pixel is characterized by its hue, saturation, and intensity (or value) coordinates (HSI). Hue is measured around the circumference of the cylinder, and has values between 0 and 360 (fig. 5). 


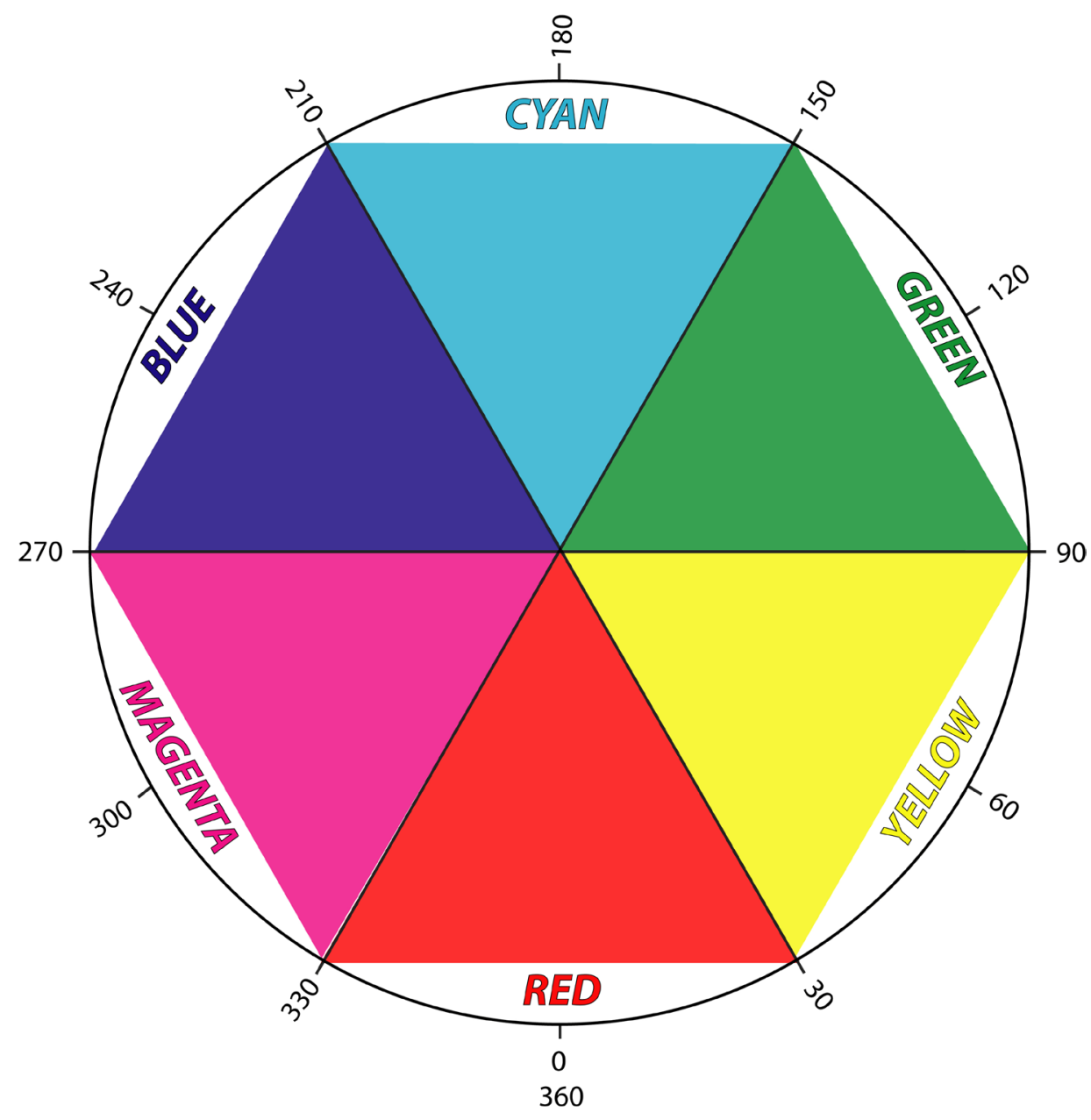

Figure 5. Range of hue values (0-360) produced during conversion composite images of Red-Green-Blue color coordinates to Munsell color coordinates and the position of the six basic hues.

Saturation is the length of the radius perpendicular to the vertical axis of the cylinder and is a measure of the vibrancy of the hue in the pixel. Intensity is measured along the vertical axis and measures the brightness of the hue in the pixel. Experience has shown that in the analysis of Landsat TM color-ratio composite images, the hue and the brightness are more important in characterizing the color than the saturation. The hue identifies which mineral group is present; the brightness measures how strong (large) the identifying ratio value is and can be used in thresholding for only the strongest responses. For visual interpretation of Landsat TM color-ratio composite images, however, the saturation component can be increased for all pixels by contrast stretching to produce an image that is more colorful and, consequently, easier to analyze.

Using the Environment for Visualizing Images (ENVI) image processing software, the Landsat TM color-ratio composite mosaic image data were converted to HSI coordinates (Environment for Visualizing Images, 1997). Based on the three classes of potentially hydrothermally altered rocks defined for the color-ratio composite mosaic image described above, three hue classes were defined: (1) green/cyan = hue 91-180, (2) magenta $=$ hue 270-330, and (3) yellow $=$ hue 30-90. In addition, only pixels with intensities greater than 182 were selected to assure that only pixels with the strongest responses were included. Each of the classified pixels was assigned a unique DN in the resulting classified image according to the mineral group it represents (table 2). 
Table 2. Criteria for classifying Landsat TM color-ratio composite image mosaic for conversion to vector polygons.

\begin{tabular}{|c|c|c|c|c|}
\hline Mineral group & Image color & Hue range (H) & Intensity (I) & $\begin{array}{c}\text { Classified data } \\
\text { number }\end{array}$ \\
\hline Ferric iron & green/cyan & $91-180$ & $>182$ & 1 \\
\hline $\begin{array}{c}\text { Clay-carbonate- } \\
\text { sulfate-mica }\end{array}$ & magenta & $270-330$ & $>182$ & 3 \\
\hline $\begin{array}{c}\text { Ferric iron + clay- } \\
\text { carbonate-sulfate- } \\
\text { mica }\end{array}$ & yellow & $30-90$ & $>182$ & 2 \\
\hline
\end{tabular}

The effect of thresholding by intensity clearly is demonstrated in the lower (south) part of the study area in figures 3 and 6 . The medium to dark green in figure 3 is because of brown to tan, ironstained clastic Pleistocene and Quaternary sediments in the San Luis Valley and is not related to hydrothermally altered rocks. In figure 6 many of these darker greens have been eliminated by applying the intensity criterion. 


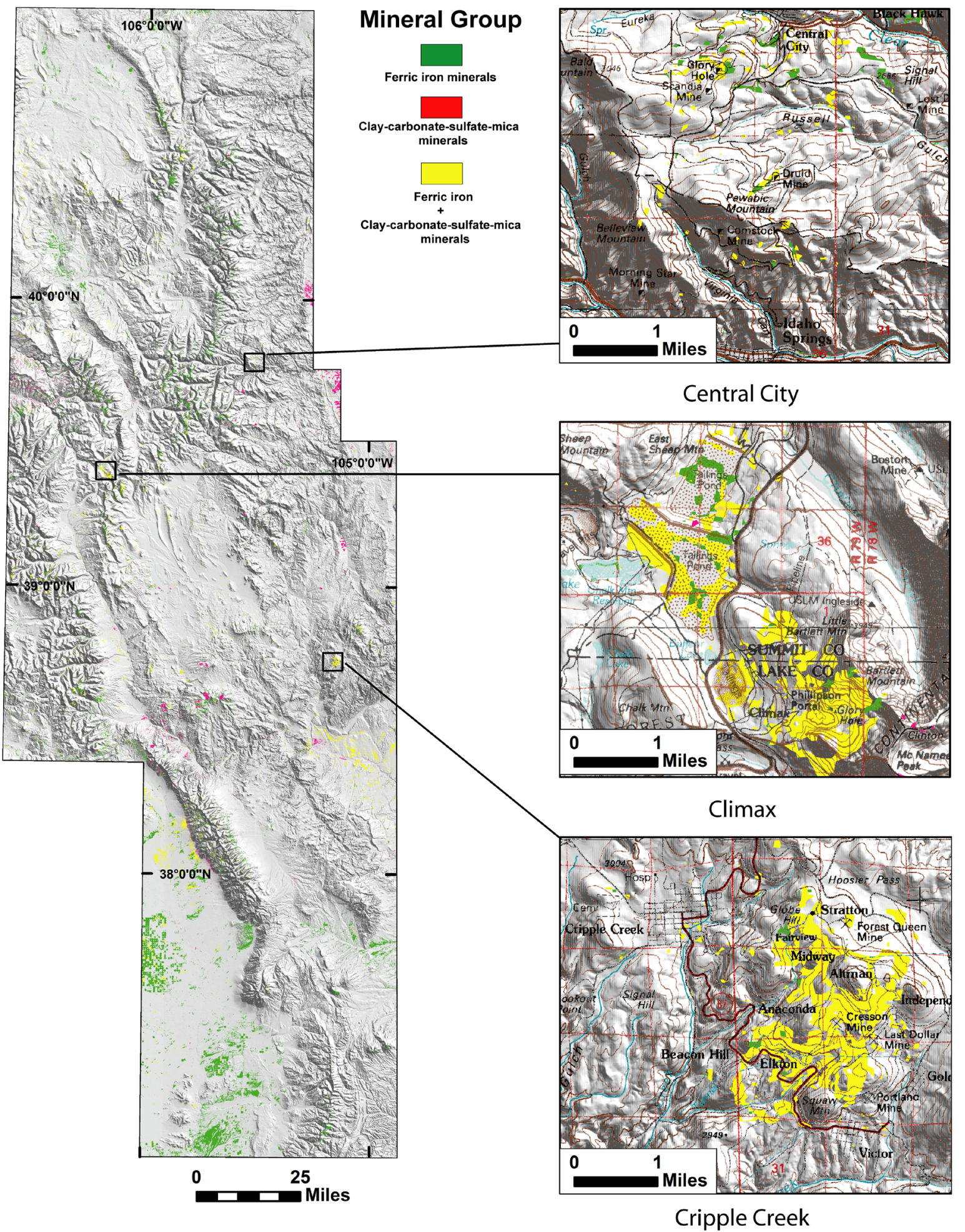

Figure 6. Filtered and vectorized Landsat Thematic Mapper (TM) color-ratio composite image mosaic data of the Central Colorado Assessment Project (CCAP) study area showing areas of potentially hydrothermally altered rocks. Insets show hydrothermally altered rocks in well-known mineral districts and provide an indication of the level of detail that is attained with the vectorized Landsat data analysis. 


\section{Spatial Filtering and Conversion to Vector Polygons}

To remove noise in the classified image related to isolated pixels and enhance concentrations of classified pixels, two spatial filters were applied to the data. The first removes the isolated pixels in the class (speckle). The second filter generalizes the display by applying a smoothing function that groups together adjacent classified pixels into a single clump. The filters used are the sieve and clump functions in ENVI, respectively. In addition to producing a classified image that focuses on distinct concentrations of classified pixels that might represent potentially hydrothermally altered rocks, the filtering procedure also greatly reduces the number of polygons that are necessary to represent the data as vectors.

The final step in preparing the Landsat TM color-ratio composite image mosaic data for use in a GIS system was to convert the filtered classified image into vector polygons. The ENVI image processing system has a conversion function that produces the vector polygons for an individual class in a classified raster image. The conversion function was run to generate polygons for each of the three mineral group classes and the three polygon files were merged into a single Environmental Systems Research Institute (ESRI) shapefile, "a vector data storage format for storing the location, shape, and attributes of geographic features" ( Minami, 2000).

\section{Characteristics of Potential Alteration Shapefile (TM_potential_alteration.shp)}

A total of 103,321 polygons was generated from the classified and filtered Landsat TM colorratio composite image mosaic data of the Central Colorado Assessment Project study area (TM_potential_alteration.shp). Of these polygons, 52.4 percent $(54,188)$ are areas containing the ferric iron mineral group. Polygons identifying areas containing the clay-carbonate-sulfate-mica mineral group are 14.4 percent $(14,851)$ and 33.2 percent $(34,282)$ of the polygons contain both the ferric iron and the clay-carbonate-sulfate-mica mineral groups. Each polygon has two attributes that describe what the polygon represents. The first attribute (Gridcode) is a numerical representation of which mineral group class the polygon represents and is keyed to the classified DN factor shown in table 2. The second attribute (mineral group) is merely a text statement of which mineral group the polygon represents.

The overall effect of thresholding and filtering of the Landsat TM color-ratio composite image mosaic data prior to converting to vector polygons is illustrated by comparing the potential hydrothermal alteration expression on the image mosaic in figure 3 (especially the insets) with the same areas represented by the vector polygons in figure 6 . The most noticeable difference is the overall lower density of the areas identified as having one or more of the mineral groups. Yet the known mineral districts containing hydrothermally altered rocks shown in the insets in figure 3 and 6 clearly are still identified. An additional positive effect of the thresholding is apparent in the Cripple Creek inset of these figures. In the Landsat TM color-ratio composite image mosaic (fig. 3) there are conspicuous patches of red in the lower left corner of the inset. These red areas are small clouds that produce a false anomaly of the clay-carbonate-sulfate-mica mineral group. However, because the clouds have red hues they were eliminated by the hue criterion for selection.

\section{References Cited}

Environment for Visualizing Images, 1997, ENVI version 3.0 user's guide: The Environment for Visualizing Images, Lafayette, Colorado, 614 p.

Knepper, D.H., Jr., 1989, Mapping hydrothermal alteration with Landsat Thematic Mapper data, in Lee, Keenan, ed., Remote sensing in exploration geology — A combined short course and field trip: 28th International Geological Congress Guidebook T182, p. 13-21. 
Minami, Michael, 2000, Using ArcMap GIS by ESRI: Environmental Systems Research Institute, Redlands, California, 528 p.

National Aeronautics and Space Aadministration, 2009, Chapter 6 - Data properties: Landsat-7 science data users handbook, accessed December 28, 2009, at http://landsathandbook.gsfc.nasa.gov/handbook/handbook_htmls/chapter6/chapter6.html.

Raines, G.L, and Knepper, D.H., Jr., 1983, A hue-saturation-intensity transformation to improve hydrothermal alteration mapping: Institute of Electrical and Electronics Engineers Digest, v. 2, p. $1.1-1.3$.

Rouse, J.W., Haas, R.H., Schell, J.A., and Deering, D.W., 1973, Monitoring vegetation systems in the great plains with ERTS: Third ERTS Symposium, National Aeronautics and Space Aadministration SP-351, v. 1, p. 309-317. 